\title{
Sudden rupture of small pseudoaneurysm of the radial artery in a patient with Covid-19 pneumonia
}

Daniela Mazzaccaro ${ }^{1}$, Matteo Giannetta ${ }^{1}$, Giovanni Malacrida ${ }^{1}$, Dino Zilio ${ }^{1}$, Alfredo Modafferi ${ }^{1}$, Paolo Righini ${ }^{1}$, Massimiliano Marrocco-Trischitta ${ }^{1}$, Luca Vaienti ${ }^{1}$, and Giovanni Nano ${ }^{1}$

${ }^{1}$ IRCCS Policlinico San Danato

January 18,2021

\begin{abstract}
We report the case of sudden rupture of a radial artery small pseudoaneurysm (PSA) occurring in a 63-years-old patient who had been hospitalized for COVID-19 pneumonia.
\end{abstract}

\section{Hosted file}

Case report.pdf available at https://authorea.com/users/390127/articles/504563-suddenrupture-of-small-pseudoaneurysm-of-the-radial-artery-in-a-patient-with-covid-19pneumonia
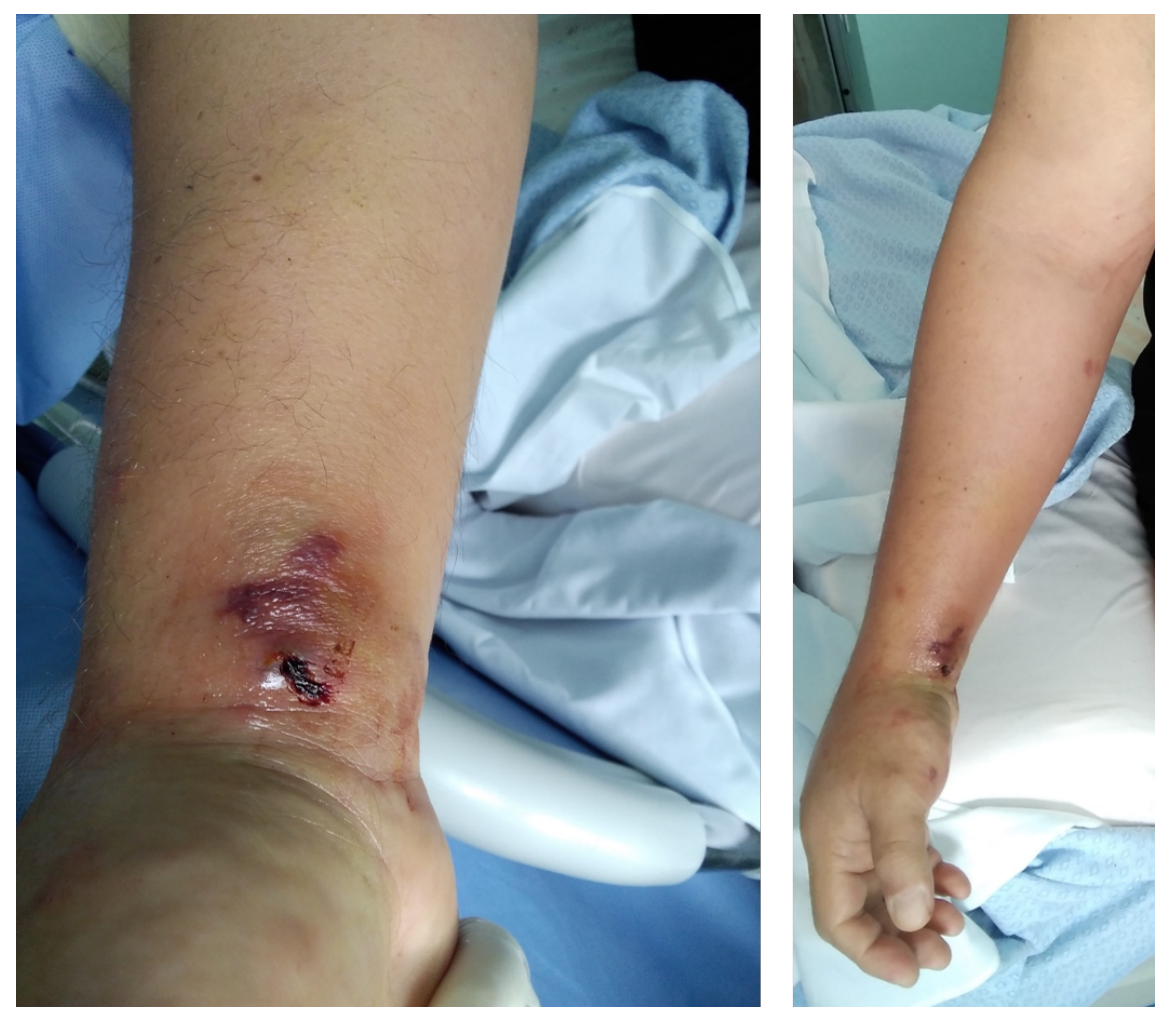


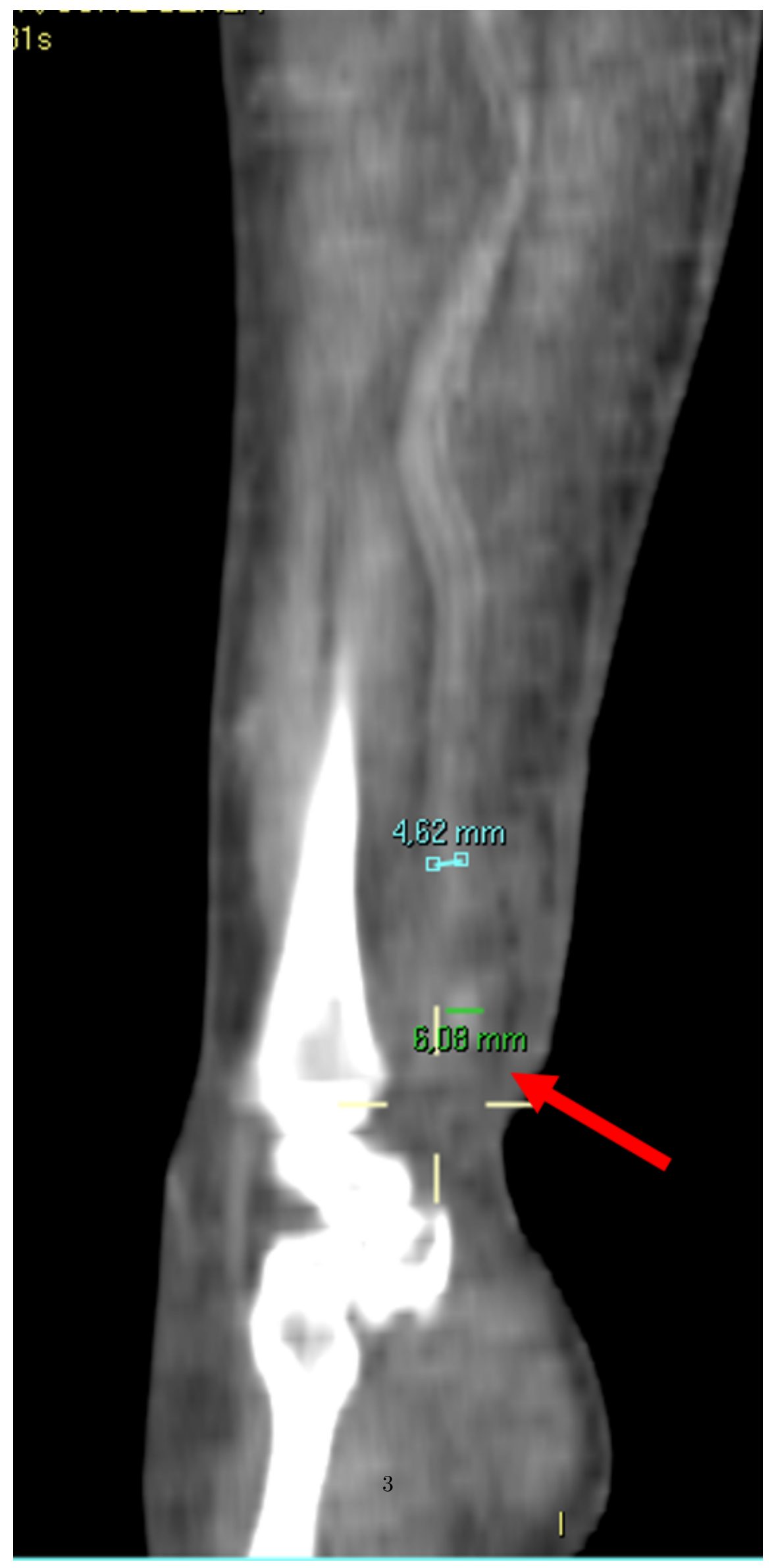



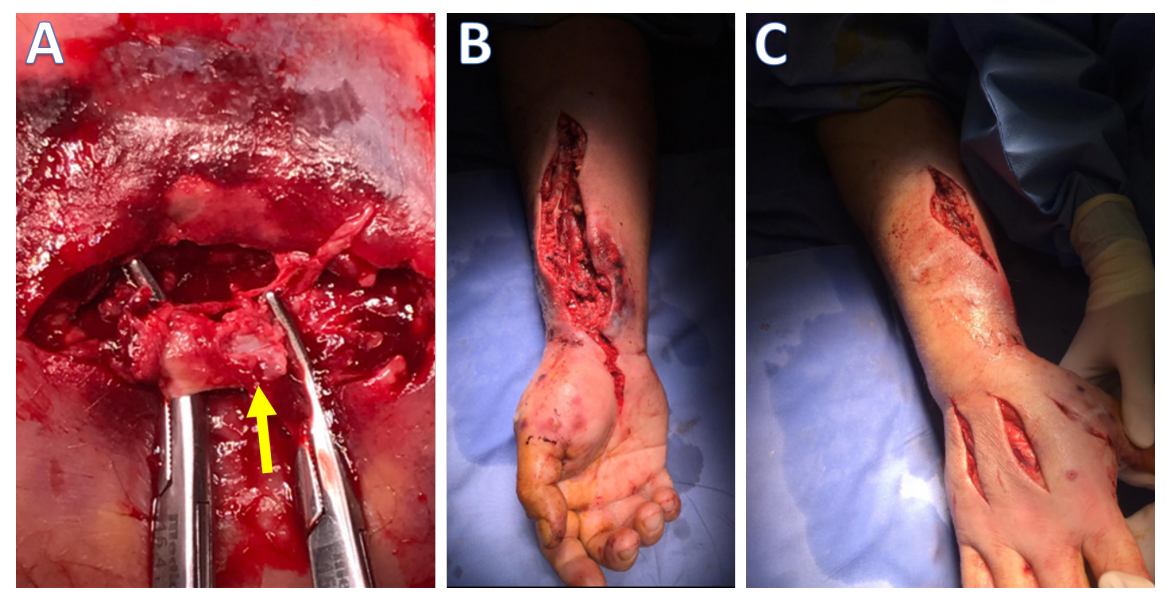